\title{
Sistem Pendukung Keputusan Penerima Beasiswa Bidikmisi dengan Metode AHP Dan Fuzzy AHP
}

\author{
Made Hanindia Prami Swari ${ }^{1}$, Moch.Taufiq. ${ }^{2}$, Faisal Muttaqin ${ }^{3}$ \\ ${ }^{1,2,3}$ Informatika, Fakultas Ilmu Komputer, Universitas Pembangunan Nasional "Veteran" Jatim \\ 1madehanindia.fikeupnjatim.ac.id \\ $\underline{2} 17 \overline{01010080 @ \text { student.upnjatim.ac.id }}$ \\ - faisalmuttaqin.if@upnjatim.ac.id
}

\begin{abstract}
Abstrak - Mahasiswa yang menempuh pendidikan pada suatu perguruan tinggi memiliki peluang utuk mendapatkan bantuan pendidikan berupa berasiswa dari berbagai sumber. Salah satu beasiswa yang paling banya peminatnya adalahbeasiswa Bidik Misi, sehingga tak heran setiap tahun terdapat banyak sekali pendaftar calon penerima beasiswa ini. Peneliian ini dibuat untuk membangun sistem penyeleksian calon penerima beasiswa secara tepat dan cepat. Dengan adanya sistem pendukung keputusan ini dapat membantu proses penyeleksian penerimaan beasiswa dengan lebih efisien. Sistem pendukung keputusan ini menggunakan dua metode yaitu Analytic Hierarchy Process dan menggunakan Fuzzy Analytic Hierarchy Process. Dimana dalam metode AHP memiliki peran dalam penentuan kriteria dan pemberian nilai bobot awal kriteria serta melakukan uji konsisten terhadap nilai dari suatu bobot awal kriteria, lalu dilanjut dengan pengolahan data hingga melakukan perangkingan dengan menggunakan pendekatan fuzzy AHP dengan algoritam Triangular fuzzy number. Hasil akhir dari sistem ini beruapa sebuah hasil perangkingan dimana para hasil dapat dilihat dengan mengurutkan urutan paling atas hingga batas kouta maksimal penerima beasiswa. Hasil uji ketepatan perhitungan sistem dengan penggunaan metode AHP dan FAHP dengan hasil real memiliki presentasi sebesar $70 \%$.
\end{abstract}

Kata Kunci- Beasiswa, Bidikmisi, Analytic Hierarchy Process, Fuzzy, Triangular fuzzy number.

\section{PENDAhULUAN}

Beasiswa dapat diartikan sebagai bentuk penghargaan yang diberikan kepada individu agar dapat melanjutkan pendidikan ke jenjang yang lebih tinggi [1]. Beasiswa diberikan baik dari instansi ataupun pemerintah. Hal ini tetunya juga berlaku di Universitas Pembangunan Nasional "Veteran" Jawa Timur. Semua mahasiswa aktif yang menempuh pendidikan di UPN "Veteran" Jawa Timur memiliki kesempatan untuk memperebutkan berbagai beasiswa yang ditawarkan Perguruan Tinggi. Salah satu beasiswa dengan peminat terbesar adalah beasiswa bidikmisi. Dalam satu periode pendaftaran terdapat lebih dari 1000 jumlah pelamar beasiswa yang ingin memperebutkan beasiswa tersebut. Dengan jumlah pegawai yang menyeleksi dan dalam waktu terbatas, maka hal ini menjadi masalah tersendiri untuk menentukan mahasiswa yang dianggap paling layak menerima beasiswa tersebut sesuai kriteria yang ditentukan, yakni berdasarkan nilai akademik mahasiswa, penghasilan orangtua atau wali, tanggungan keluarga dan lainlain. Permasalahan lain yang dapat diakibatkan dari seleksi secara manual adalah kemunkginan terjadinya subjektifikas dalam menentukan penerima beasiswa. Untuk menanggulangi permasalahan terseut maka dapat dibangun sebuah Sistem Pendukung Keputusan untuk membantu memberikan rekomendasi peneria beasiswa bidikmisi sesuai kriteria yang ditentukan.

Terdapat banyak penelitian yang telah dilakukan terkait pembuatan sebuah sistem pendukung keputusan penerima beasiswa. Penelitian terkait topik ini pernah dilakukan oleh Heru Saputra, dkk yang menyatakan bahwa metode AHP mampu menyeleksi alternatif terbaik dari sejumlah alternatif, dalam hal ini alternatif yang dimaksudkan yaitu yang berhak menerima beasiswa berdasarkan kriteria-kriteria yang ditentukan [2]. Namun, dalam penentuan suatu keputusan banyak faktor yang mempengaruhi pengambilan keputusan, sehingga dirasa perlu adanya identifikasi dari berbagai faktor penting dan mempertimbangkan pengaruh suatu faktor dengan faktor lainnya. Permasalahan ini pernah diteliti oleh Yesi Yusmita, dkk pada penelitian Penelitian ini membahas tentang penggunaan metode Fuzzy AHP dengan konsep menggunakan pembobotan non additive. Hal ini dilakukan untuk menangani kelemahan AHP dalam mengmabil keputusan dengan banyak kriteria yang bersifat subjektif [3]. Oleh karena itu pengunaan sistem pengambil keputusan dengan metode Fuzzy Analytic Hierarchy Process (AHP) digunakan dalam penelitian ini. Pada dasarnya konsep dari pengambil keputusan adalah memilih alternative. Dengan penggunaan metode AHP sebagai peralatan utama dalam sistem pengambil keputusan memiliki banyak keunggulan dalam menjelaskan proses pengambil keputusan. Namun metode AHP sendiri memiliki kekurangan karena dianggap tidak seimbang dalam skala penilaian matriks berpasangan [4]. Skala dari AHP sendiri adalah berbentuk 'crips' yang dianggap kurang mampu untuk menangani ketidakpastian sehingga patut dipertimbangkan dengan adanya penggunaan pendekatan logika Fuzzy.

Dengan pendekatan logika Fuzzy yang merupakan sebuah logika yang mempunyai nilai kekaburan atau kesamaan antara dua nilai, khususnya Triangullar Fuzzy terhadap skala AHP diharapkan mampu meminimalisasi ketidakpastian sehingga diharapkan mendapatkan hasil yang lebih akurat. Dengan 
adanya penggunaan metode Fuzzy-AHP maka tiap pendaftar beasiswa bidikmisi tidak semua akan menerima bidikmisi. Meskipun para pendaftar telah memenuhi semua kriteriakriteria yang sudah ditetapkan. Karena dengan penggunaan metode FuzzyAHP memberikan pertimbangan prioritas dengan memperhitungkan segala kriteria yang mendukung pengambilan keputusan, dimana metode Fuzzy-AHP dinilai sangat membantu, mempercepat dan mempermudah menghasilkan hasil yang akurat dalam proses pengambil keputusan.

Penelitian ini menggunakan perpaduan metode AHP dan Fuzzy AHP karena metode AHP memiliki kelemahan terhadap kriteria yang memiliki sikap subjektif yang lebih banyak, oleh karna itu dengan menggunakan pendekatan Fuzzy AHP maka permasalahan pada kriteria dapat dipandang lebih objektif. Sistem ini akan bekerja sebagai pendukung keputusan dalam penerimaan beasiswa bidikmisi. Cara kerja sistem bergerak secara dinamis diawali dengan memasukkan data mahasiswa sesuai kriteria yang sudah ditentukan, lalu memasukkan perbandingan kriteria yang sudah ditentukan, lalu sistem akan melakukan perhitungan perangkingan dengan menggunakan algoritma Triangular Fuzzy, hasil akhir sistem ini adalah sebuah hasil perangkinan urutan penerima beasiswa, dengan hasil mahasiswa yang berada diurutan paling atas adalah mahasiswa yang dianggap paling berhak mendapatkan bantuan beasiswa bidikmisi.

\section{TINJAUAN PUSTAKA}

\section{A. Analytic Hierarchy Process (AHP)}

Tujuan utama AHP adalah untuk membuat rangking alternatif keputusan dan memilih salah satu yang terbaik bagi kasus multi Kriteria yang menggabungkan faktor kualitatif dan kuantitatif di dalam keseluruhan evaluasi alternatif alternatif yang ada. AHP digunakan untuk mengkaji permasalahan yang dimulai dengan mendefinisikan permasalahan tersebut secara seksama kemudian menyusunnya ke dalam suatu hirarki. AHP memasukkan pertimbangan dan nilai-nilai pribadi secara logis. Proses ini bergantung pada imajinasi, pengalaman, dan pengetahuan untuk menyusun hirarki suatu permasalahan dan bergantung pada logika dan pengalaman untuk memberi pertimbangan. Tahapan-tahapan proses dalam metode AHP [5] adalah :

a) Mendefinisikan masalah dan menentukan tujuan yang diinginkan.

b) Membuat struktur hirarki yang diawali dengan tujuan umum, dilanjutkan dengan kriteria-kriteria dan alternatifalternatif pilihan.

c) Membentuk matriks perbandingan berpasangan yang menggambarkan pengaruh setiap elemen terhadap masing-masing kriteria.

d) Menguji konsistensi hirarki. Jika nilai konsistensi rasio yang dihasilkan tidak memenuhi standar yang ditetapkan yaitu Consistency Ratio $(\mathrm{CR})<0,1$ maka penilaian harus diulang kembali.

\section{B. Prinsip Dasar AHP}

Terdapat beberapa prinsip yang harus dipahami dalam menyelesaikan permasalahan menggunakan AHP [6] :
1. Penyusunan Hirarki Merupakan langkah penyederhanaan masalah ke dalam bagian yang menjadi elemen pokoknya, kemudian ke dalam bagian-bagiannya lagi, dan seterusnya secara hirarki agar lebih jelas, sehingga mempermudah pengambil keputusan untuk menganalisis dan menarik kesimpulan terhadap permasalahan tersebut.

2. Menentukan prioritas AHP melakukan perbandingan berpasangan antar dua elemen pada tingkat yang sama. Kedua elemen tersebut dibandingkan dengan menimbang tingkat preferensi elemen yang satu terhadap elemen yang lain berdasarkan kriteria tertentu.

3. Konsistensi logis Konsistensi logis merupakan prinsip rasional dalam AHP. Konsistensi berarti dua hal, yaitu : a. Pemikiran atau objek yang serupa dikelompokkan menurut homogenitas dan relevansinya. b. Relasi antar objek yang didasarkan pada criteria tertentu, saling membenarkan secara logis

\section{Struktur Hirarki}

Hirarki merupakan gambaran dari permasalahan yang kompleks dalam struktur banyak tingkat dimana tingkat paling atas adalah tujuan dan diikuti tingkat kriteria, subkriteria dan seterusnya ke bawah sampai pada tingkat yang paling bawah adalah tingkat alternatif

\section{Konsistensi Perbandingan Matriks Berpasangan}

Uji konsistensi dilakukan dengan menguji konsistensi index dan uji rasio terhadap nilai bobot awal yang sudah ditentukan. Uji konsistensi dilakukan untuk mendapatkan keputusan yang valid. matriks perbandingan berpasangan dinyatakan konsisten apabila nilai consistency ratio $(\mathrm{CR}) \leq$ $10 \%$ dan Jika CI bernilai nol, berarti matriks konsisten [7]. Batas ketidak konsistenan (inconsistency) yang ditetapkan diukur dengan menggunakan Consistency Ratio(CR), yakni perbandingan indeks konsistensi dengan nilai Random Indeks(RI). Berikut merupakan cara untuk mencari nilai CR, yang pertama yaitu mencari nilari CI sebagai berikut :

a) $C I=\frac{(\lambda-\mathrm{n})}{(n-1)}$

(1)

$\mathrm{CI}=$ konsitensi index

$\mathrm{n}$ = banyak jumlah kriteria

setelah mendapat nilai CI selanjutnya kita dapat mencari nilai indeks rasi untuk melihat apa valid tidaknya sebuah nilai bobot teserbut dari uji konsistensi ini, berikut merupakan cara mencari nilai CR :

b) $C R=\frac{C I}{R I}$

$\mathrm{CR}=$ konsistensi raiso

$\mathrm{RI}=$ random index

TABEL I

NILAI RANDOM INDEX

\begin{tabular}{|c|c|c|c|c|c|c|c|c|c|c|}
\hline $\mathrm{N}$ & 1 & 2 & 3 & 4 & 5 & 6 & 7 & 8 & 9 & 10 \\
\hline$R I$ & 0. & 0. & 0. & 0. & 1. & 1. & 1. & 1. & 1. & 1. \\
& 00 & 00 & 52 & 89 & 11 & 25 & 35 & 40 & 45 & 49 \\
\hline
\end{tabular}




\section{E. Fuzzy Analytical Hierarchy Process}

Metode Fuzzy Analytical Hierarchy Process atau bias disebut F-AHP adalah gabungan metode AHP dengan menggunakan pendekatan logika fuzzy. Pengunaan metode Fuzzy AHP didasari dengan adanya kelemahan yang dimiliki oleh metode AHP itu sendiri yaitu permasalahn terhadap kriteria yang memiliki subjektif yang lebih banyak dan skala dari AHP sendiri adalah berbentuk 'crips' yang dianggap kurang mampu untuk menangani ketidakpastian. Logika fuzzy tidak hanya mengenal dua keadaan tetapi juga mengenal keadaan yang berkisar dari salah sampai benar [8]. Dengan penggunaan Fuzzy AHP ini maka permasalahan terhadap kriteria dapat dipandang dengan objektif dan akurat. Langkah penyelesaian masalah dengan metode Fuzzy AHP hampir sama dengan metode AHP. Hanya saja metode Fuzzy AHP mengubah skala AHP ke dalam skala triangular fuzzy untuk memperoleh prioritas. Data yang telah diubah tersebut diproses lebih lanjut dengan extent analysis [9].

\section{F. Triangular Fuzzy Number}

Traingular Fuzzy merupakan salah satu dari pendekatan metode AHP dengan Fuzzy, dimana fungsi Fuzzy sendiri adalah untuk mengatasi kelemahan yang ada pada metode AHP yaitu ketidakmampuan dalam mempertimbangkan ketidakpastian dalam skala yang dimiliki AHP berbentuk bilangan 'crips' [4]. Pada dasarnya Triangular Fuzzy atau bisa disebut Triangular Fuzzy Number (TFN) merupakan teori himpunan fuzzy yang membantu dalam pengukuran dan perbandingan yang berhubungan dengan subjektif manusia dengan menggunakan Bahasa linguistic yaitu (medium, upper, lower) atau biasa disebut $\mathrm{m}, 1$,u.penggunaan triangular fuzzy number sendiri yaitu dengan cara melakukan fuzzifikasi pada skala AHP sehingga dengan itu maka akan diperoleh skla baru yang disebut skala Fuzzy AHP

TABEL II

TABEL SKALA NILAI FUZZY (CHANG, 1996)

\begin{tabular}{|c|l|c|c|}
\hline $\begin{array}{l}\text { Intesitas } \\
\text { Kepentingan } \\
\text { AHP }\end{array}$ & $\begin{array}{l}\text { Himpunan } \\
\text { Linguistik }\end{array}$ & $\begin{array}{l}\text { Triangular } \\
\text { Fuzzy } \\
\text { Number } \\
(\mathrm{TFN})\end{array}$ & Recriprocal \\
\hline 1 & $\begin{array}{l}\text { Perbandingan } \\
\text { elemen yang sama }\end{array}$ & $(1,1,1)$ & $(1,1,1)$ \\
\hline 2 & Pertengahan & $(1 / 2,1,3 / 2)$ & $(2 / 3,1,2)$ \\
\hline 3 & $\begin{array}{l}\text { Elemen yang satu } \\
\text { cukup penting dari } \\
\text { lainnya }\end{array}$ & $(1,3 / 2,2)$ & $(1 / 2,2 / 3,1)$ \\
\hline 4 & $\begin{array}{l}\text { Pertengahan satu } \\
\text { lebih cukup } \\
\text { penting dari pada } \\
\text { lainnya }\end{array}$ & $(3 / 2,2,5 / 2)$ & $(2 / 5,1 / 2,2 / 3)$ \\
\hline 5 & $\begin{array}{l}\text { Elemen satu kuat } \\
\text { pentingnya dengan } \\
\text { yang lain }\end{array}$ & $(2,5 / 2,3)$ & $(1 / 3,2 / 5,1 / 2)$ \\
\hline 6 & $\begin{array}{l}\text { Pertengahan } \\
\text { Elemen yang satu } \\
\text { lebih kuat dari } \\
\text { yang lainnya }\end{array}$ & $(5 / 2,3,7 / 2)$ & $(2 / 7,1 / 3,2 / 5)$ \\
\hline 7 & Pertengahan satu & $(7 / 2,4,9 / 2)$ & $(2 / 9,1 / 4,2 / 7)$ \\
\hline 9 & $\begin{array}{l}\text { Elemen } \\
\text { mutlak lebih } \\
\text { penting dari yang } \\
\text { lainnya }\end{array}$ & $(4,9 / 2,9 / 2)$ & $(2 / 9,2 / 9,1,4)$ \\
\hline
\end{tabular}

\section{G. Menghitung Nilai Synthetic Fuzzy}

Analisa fuzzy synthetic extent dipakai untuk memperoleh perluasan suatu objek dalam memenuhi tujuan yang disebut satisfied extent [10]. Menghitung nilai Synthetic Fuzzy diperlukan untuk menilai tujuan matriks perbandingan dengan menilai bobot pada setiap kriteria terhadap tujuan utama hirarki. Perhitungan dengan menggunakan Analisa fuzzy synthetic extent metode [9] yaitu dengan menentukan nilai sintesis fuzzy sehingga akan mendapatkan nilai vektor bobot setiap elemen hirarki atau nilai bobo tiap kriteria. Beikut merupakan persamaan untuk mendapatkan nilai sintesis fuzzy : a) Fuzzy synthetic extend di definisikan sebagai berikut :

$$
S i=\sum_{j-1}^{m} m{ }_{g j}^{j} \otimes\left|\sum_{n-1}^{n} \quad \sum_{j-1}^{m} M_{g i}^{j}\right|^{-1}
$$

Setelah mendapatkan nilai sinesis fuzzy kemudan kita melakukan deffuzifikasi terhadapa nilai sisntesis tersebut agar mendapatkan nilai bobo vektor dari setiap kriteria.

b) Defuzzifikasi dapat dilihat sebagai berikut :

$D M_{i} \frac{\left(u_{i}-l_{i}\right)+\left(m_{i}-l_{i}\right)}{3}$

(4)

$M_{i}=l_{i}, m_{i}, u_{i}$

Dengan persamaan (5) kita sudah mendapatkan nilai deffuzifikasi. Dan selanjutnya yaiut melakukan normalisasi nilai deffuzifikasi dengan nilai hasil jumlah seluruh nilai deffuzifkasi. Dan dari hasil tersebut akan menjadi bobot kriteria yang akan digunakan dalam proses penentuan penerimaan beasiswa.

\section{MetOdOLOGI}

\section{A. Rancangan Penelitian}

Penelitian pemebuatan sistem pendukung keputusan penetuan beasiswa bidikmisi dengan menginplementasikan metode AHP dengan pendekatan fuzzy yaitu fuzzy AHP dengan menggunakan algoritma Triangular fuzzy number. Penelitian ini dilakukan dengan studi kasus pada Universitas Pembangunan Nasional "Veteran" Jawa Timur.

\section{B. Analisa Data}

Dataset penelitian merupakan data yang akan digunakan dalam menjalankan penelitian sebagai bahan uji coba dari sistem. Data tersebut berisikan data-data mahasiswa pendaftar beasiswa bidikmisi. Data ini diberi oleh salah satu ketua tim penyelenggara beasiswa bidikmisi. Dataset berisikan tentang data diri mahasiswa serta keterangan yang dibutuhkan dalam penlitian ini meliputi : IPK, semester, penghasilan orang tua, dan jumlah tanggungan orang tua. Pada penilitan ini terdapat 10 mahasiswa yang terverifikasi mendapatkan bantuan beasiswa dan 10 mahasiswa yang tidak terverifikasi untuk mendapat beasiswa.

\section{Analisis dan Rancangan Sistem}

Dalam pembuatan sistem ini diawali dengan mempersiapkan data-data mahasiswa pendafatar beasiswa yang nantinya akan dimasukkan ke dalam program atau sistem. Secara garis besar, agar penentuan penerima beasiswa bidikmisi menggunakan sistem pengambil keputusan dapat 
merekomendasikan dan juga sebagai pendukung keputusan dalam penerima beasiswa dengan tepat dan sesuai, terdapat beberapa tahapan yang harus diterapkan, yaitu:

1. Masukkan data (input) berupa data teks yang berisi tentang informasi nama mahasiswa dan semester serta penghasilan orang tua.

2. Membuat struktur hirarki sebuah masalah yang nantinya akan diselesaikan dan melakukan pembobotan pada setiap kriteria.

3. Menentukan nilai perbandingan matriks berpasangan antar kriteria dengan menggunakan skala AHP.

4. Menghitung rasio untuk melihat keakuratan hasil.

5. Menentukan sintesis Fuzzy (Si) prioritas.

6. Menghitung pembobotan bilangan Fuzzy pada masingmasing kriteria, dan jika nilai Fuzzy lebih besar dari K, Fuzzy didefinisikan menjadi nilai ordinat.

7. Melakukan normalisasi pada nilai prioritas bobot kriteria yang sudah didapatkan.

8. Keluaran (output) berupa rekomendasi nama penerima beasiswa. Sesuai dengan topik ini yang bertujuan untuk membantu pengambil keputusan dalam penentuan beasiswa bidikmisi agar bantuan bidikmisi jatuh kepada mahasiswa yang layak menerima bantuan tersebut.

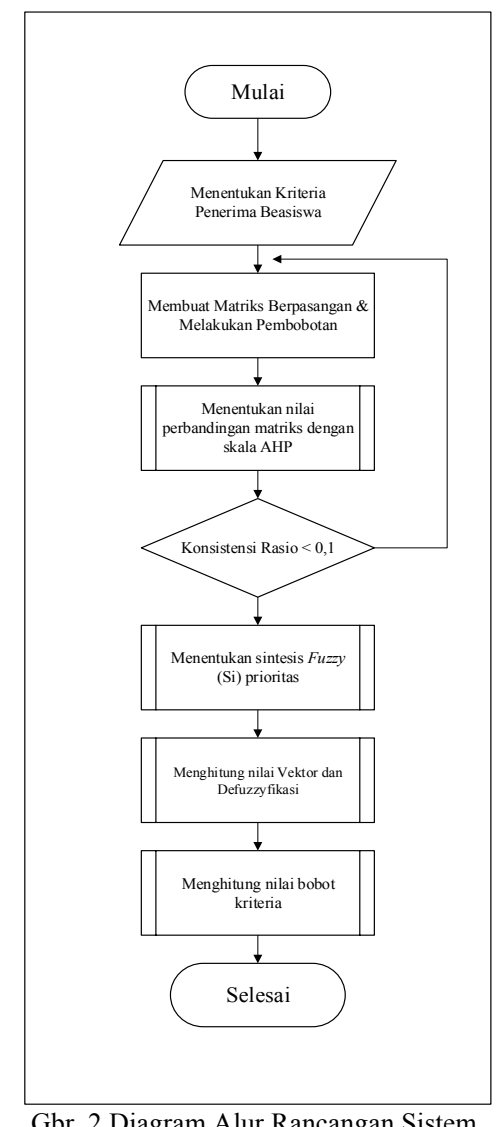

\section{Perancangan Sistem}

Pada perancangan sistem akan dijelaskan tentang beberapa pemodelan yaitu use case sistem, Conceptual Data Model (CDM), dan Physical Data Model (PDM).

a) Use case sistem

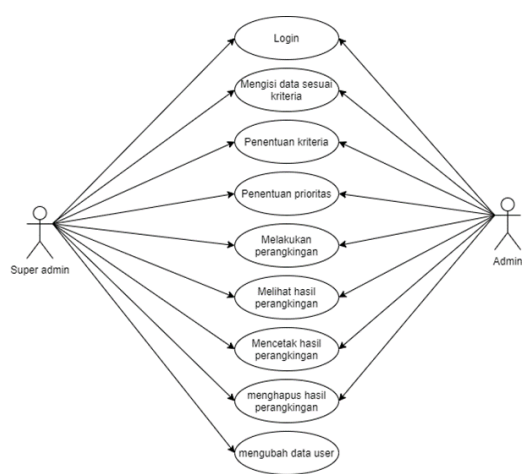

Gbr. 3 Uses Case Sistem.

b) Conceptual Data Model (CDM)

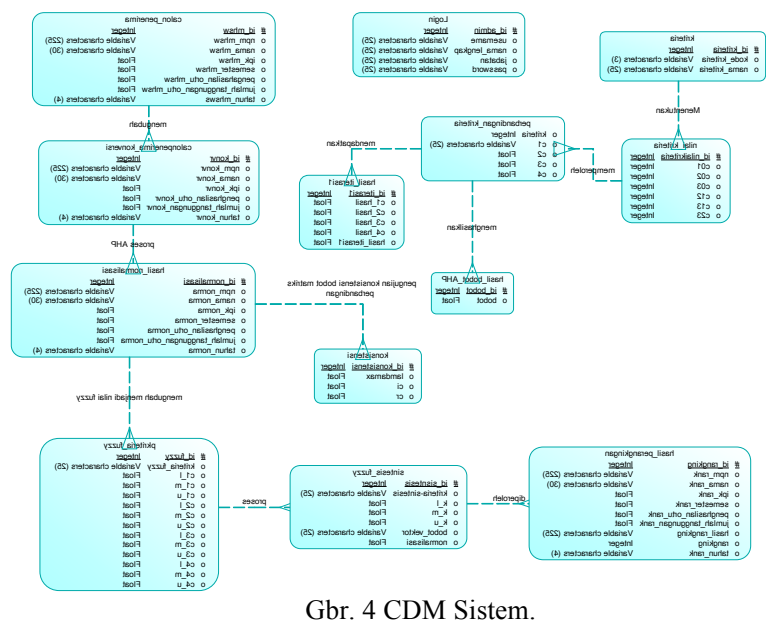

c) Physical Data Model (PDM)

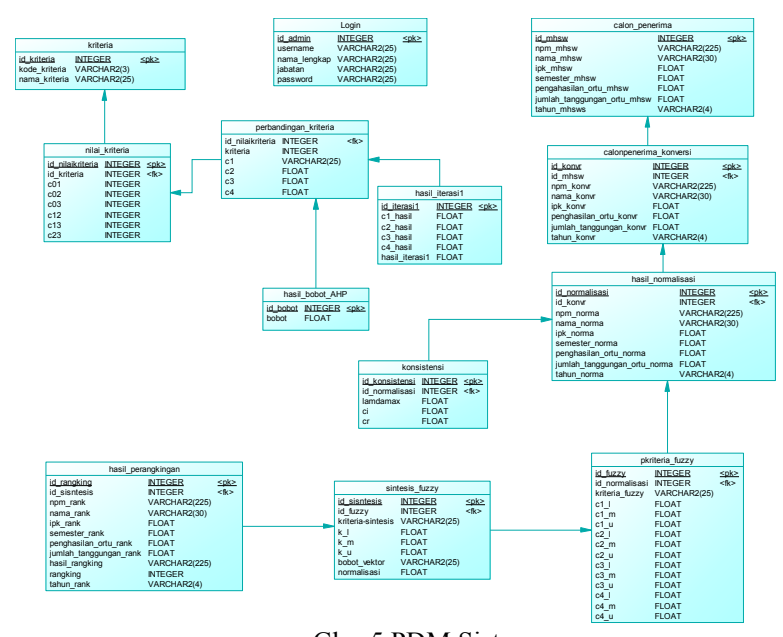

Gbr. 5 PDM Sistem.

\section{HASIL DAN PEMBAHASAN}

\section{E. Impelementasi Sistem}

Sistem pendukung keputusan yang dirancang dalam penilitian ini akan diimplementasikan kedalam bentuk aplikasi Web browse dengan menggunakan bahasa PHP dan menggunkan Mysql sebagai database. 


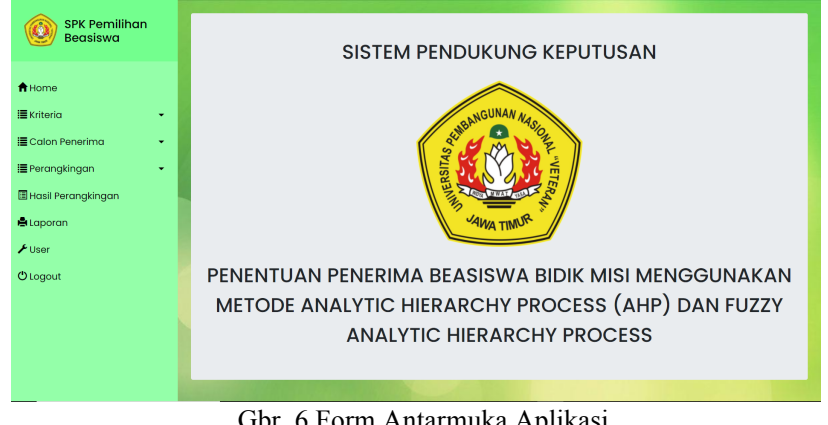

Gbr. 6 Form Antarmuka Aplikasi

F. Alur Kerja Sistem

1. Menentukan nilai bobot AHP dan uji konsistensi

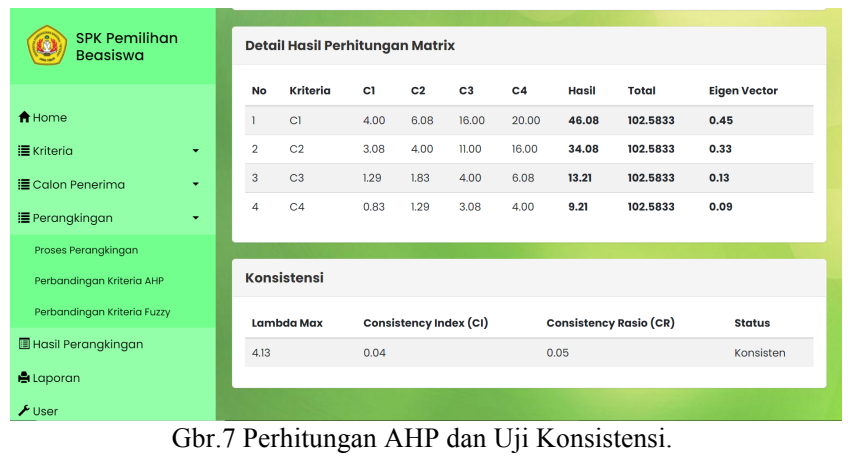

Pada tahapan ini melakukan pencarian nilai bobot dari AHP setelah mendapatkan nilai bobot AHP atau nilai eigen vector. Setelah mendapatkan nilai bobot AHP dapat melakukan uji konsistensi untuk melihat valid tidaknya suatu perbandingan nilai bobot tersebut.

2. Menghitung Synthetic Fuzzy dan melakukan normalisasi

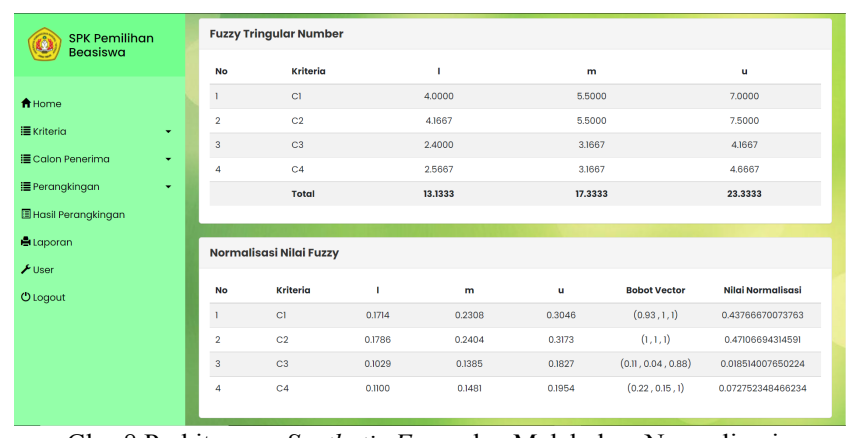

Gbr. 8 Perhitungan Synthetic Fuzzy dan Melakukan Normalisasi.

Pada tahap yaitu merubah nilai skala AHP kedalam bentuk Triangular fuzzy number. Dan setelah itu mencari nilai sintesis fuzzy dan melakukan normalisasi untuk mendapat nilai bobot kriteria yang akan digunakan dalam proses perangkingan. Nilai hasil normalisasi sebagai berikut :

a) Bobot kriteria pertama IPK : 0.43766

b) Bobot kriteia kedua Semester : 0.47106

c) Bobot kriteria ketiga Penghasilan orang tua : 0.01851

d) Bobot kriteria keempat Jumlah tanggungan orang tua : 0.07275

\section{G. Hasil Perangkingan}

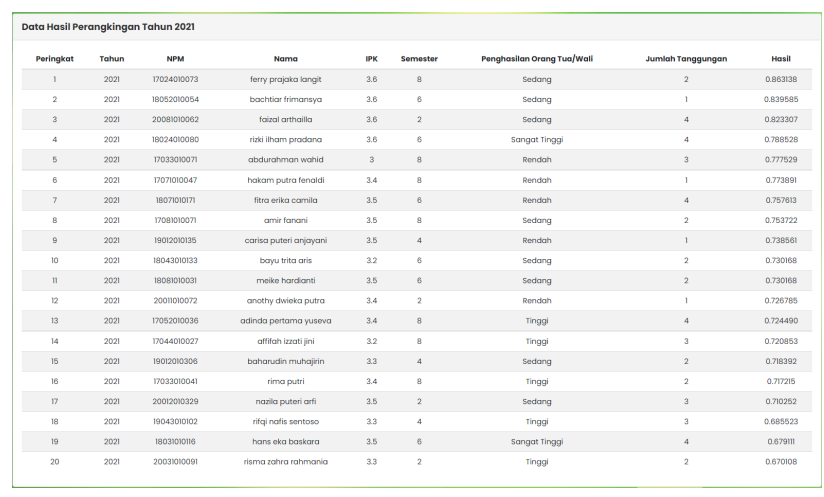

Gbr. 9 Hasil Perangkingan

Hasil perangkingan dapat dilihat untuk mahasiswa penerima beasiswa diurutkan dari urutan paliang hingga batas kouta penerima beasiswa. Hasil perangkingan didapat dari nilai normalisasi bobot vektor dari proses defuzzifikasi dengan hasil konversi nilai kriteria para pendaftar beasiswa.

\section{H. Uji Coba Perhitungan Sistem}

Uji coba perhitungan dilakukan untuk melihat seberapa dekat hasil yang didapatkan oleh sistem dengan hasil manual. Uji coba ini dilakukan dengan membandingkan hasil perhitungan sistem dengan hasil perhitungan manual atau Real. Nomor halaman, header dan footer tidak dipakai.

TABEL III

TABEL PERBANDINGAN

\begin{tabular}{|c|c|c|c|}
\multicolumn{5}{|c|}{ TABEL PERBANDINGAN } \\
\hline \multirow{2}{*}{ Nama } & \multirow{2}{*}{ Peringkat sistem } & Hasil manual & Keterangan \\
\hline M & 1 & D & sesuai \\
\hline T & 2 & D & sesuai \\
\hline R & 3 & TD & tidak sesuai \\
\hline H & 4 & D & sesuai \\
\hline L & 5 & D & tidak sesuai \\
\hline E & 6 & TD & tidak sesuai \\
\hline J & 7 & TD & sesuai \\
\hline K & 8 & D & sesuai \\
\hline S & 9 & D & sesuai \\
\hline G & 10 & TD & tidak sesuai \\
\hline A & 11 & TD & tidak sesuai \\
\hline N & 12 & TD & tidak sesuai \\
\hline Q & 13 & D & tidak sesuai \\
\hline C & 14 & D & tidak sesuai \\
\hline I & 15 & TD & tidak sesuai \\
\hline D & 16 & TD & tidak sesuai \\
\hline F & 17 & DD & tidak sesuai \\
\hline B & 18 & & tidak sesuai \\
\hline O & 19 & 20 & \\
\hline P & & & tidak sesuai \\
\hline
\end{tabular}

Keterangan : D : diterima hasil real

TD : tidak diterima hasil real

Dari 20 data tersebut akan ditentukan True possitive (TP) jika hasil dari sistem sama dengan hasil real yang menyakatan sesuai, False positive (FP) jika hasil dari sitem menyatakan salah dan hasil real menyatakan benar, True negative (TN) jika hasil dari sistem dan real menyatakan salah, dan False 
negative (FN) jika hasil sistem mengatakan benar dan hasil real mengatkan tidak. Maka akan diperoleh hasil bedasarkan tabel yaitu $\mathrm{TP}=7, \mathrm{FP}=3, \mathrm{TN}=7, \mathrm{FN}=3$

Akurasi $=\frac{\mathrm{TP}+\mathrm{TN}}{\mathrm{TP}+\mathrm{TN}+\mathrm{FP}+\mathrm{FN}} \times 100 \%=\frac{7+7}{7+7+3+3} \times 100 \%=70 \%$

Dari hasil tersebut dapat dilihat jika perbandingan antara hasil perhitungan sistem dengan hasil perhitungan real mendapati hasil sebesar $70 \%$.

\section{KESIMPULAN DAN SARAN}

Adapun kesimpulan yang dapat diperoleh dari penilitian ini yaitu Penggunaan dua metode AHP dan F-AHP dalam sistem pendukung keputusan dapat digunakan dalam memecahkan masalah penerimaan beasiswa. Dengan penggunaan metode tersebut perbandingan nilai yang didapat sesuai dengan kriteria yang dimaksud sehingga mendapati hasil yang cukup tepat.

Hasil akhir dari sistem yaitu adanya sebuah hasil perangkingan penerima beasiswa yang menunjukan nama mahasiswa dan data-data mahasiswa. Dan Hasil rangking ditentukan dari urutan paling atas hingga kebawah batas maksimal pendapat bantuan beasiswa. Hasil yang diberikan dari ketepatan proses perangkingan sistem menggunakan metode AHP dan Fuzzy AHP dengan hasil real memiliki presentasi sebesar $70 \%$

Dengan hasil sebesar $70 \%$ dapat dikatakan dalam sistem pendukung keputusan penentuan beasiswa bidikmisi dengan menggunakan dua penggabungan metode yaitu AHP dan Fuzzy AHP dirasa dapat digunakan. Namun dalam kedepannya pengembangan sistem pendukung keputusan dengan metode AHP dan Fuzzy AHP dapat juga ditambahkan metode yang berbasis kecerdasan buatan, agar kedepannya dapat mengolah data lebih banyak secara tepat dan mendapatkan ketepatan data yang diinginkan.

\section{UCAPAN TERIMA KASIH}

Terima kasih disampaikan kepada Tim SANTIKA yang telah memberikan kami wadah untuk mengembangkan pengetahuan dan memberi wadah untuk membuat karya tulis dari hasil penilitan kami, sehingga kedepannya semoga dapat membantu memberi wawasan serta dampak positif bagi masyarakat.

\section{REFERENSI}

[1] E. Murniasih, Buku Pintar Beasiswa. Jakarta: Gagas Media, 2009.

[2] H. Saputra, E. Mardiono, I. Stephane, and R. Purwasih, "Seleksi Penerimaan Beasiswa Bidikmisi pada STMIK Indonesia Padang Menggunakan Metode (AHP)," MISI (Jurnal Manaj. Inform. dan Sist. Informasi), vol. 4, no. 1, 2021.

[3] Y. Yusmita and A. Fiatno, "Analisis Pengunaan Aplikasi Fuzzy Analytical Hierarchy Process dalam Seleksi Karyawan.," Jutin (Jurnal Tek. Ind. Terintegrasi), vol. 1, no. 2, 2018.

[4] H. Deng, "Multicriteria analysis with fuzzy pairwise comparison," Int. J. Approx. Reason., vol. 21, no. 3, 1999, doi: 10.1016/S0888613X(99)00025-0.

[5] A. Apriyanto, "Perbandingan Kelayakan Jalan Beton dan Aspal dengan Metode Analityc Hierarcy Process (AHP) (Studi Kasus Jalan Raya Demak - Godong)," Universitas Diponegoro, 2008.

[6] T. L. Saaty, Decision Making for Leaders : The Analytic Hierarcy Process for Decisions in A Complex World, Third Edit. Pittsburgh: RWS Publications, 2021.

[7] T. L. Saaty, "Decision making with the analytic hierarchy process," Int. J. Serv. Sci., vol. 1, no. 1, pp. 83-98, 2008, doi: 10.1108/JMTM-03-20140020 .

[8] S. H. Kusumadewi, "Fuzzy Multi-Attribute Decision Making (Fuzzy MADM)," Graha Ilmu Yogyakarta, 2006.

[9] D. Y. Chang, "Applications of the extent analysis method on fuzzy AHP," Eur. J. Oper. Res., vol. 95, no. 3, pp. 649-655, Dec. 1996, doi: 10.1016/0377-2217(95)00300-2.

[10] Y. M. Wang, Y. Luo, and Z. Hua, "On the extent analysis method for fuzzy AHP and its applications,” Eur. J. Oper. Res., vol. 186, no. 2, 2008, doi: 10.1016/j.ejor.2007.01.050. 